\title{
Phytochemicals from beer: identification, antioxidant activity, absorption and bioactivity
}

\author{
V. J. Collins ${ }^{1}$, D. Vauzour ${ }^{1}$, M. H. Gordon ${ }^{1}$, J. M. Ames ${ }^{2}$, C. Walker ${ }^{3}$ and J. P. E. Spencer ${ }^{1}$ \\ ${ }^{1}$ Department of Food Biosciences, The University of Reading, Whiteknights, Reading RG6 6AP, UK, ${ }^{2}$ School of Biological \\ and Food Sciences, Queen's University Belfast, Belfast BT9 5AG, UK and ${ }^{3}$ BRI, Coopers Hill Road, Nutfield RHI 4HY,
}

Surrey, $U K$

Beer is a relatively rich source of phytochemicals, including phenolic acids, hydroxycinnamates and flavonoids ${ }^{(1)}$. Such compounds, also present in a variety of foods, are widely reported for their protective effect in chronic disease development ${ }^{(2)}$. The physiological function of polyphenols in vivo is dependent on the extent of their absorption and metabolism in the gastrointestinal tract. Flavonols are metabolised to O-methylated, glucuronide and sulphate conjugates during absorption in the small intestine ${ }^{(3)}$. The majority of these metabolites are not transferred across the jejunum or ileum and as a result reach the large intestine intact, where they may impart biological activity ${ }^{(4)}$.

The polyphenol contents of lager, ale and stout and their link to antioxidant potential were investigated. Ethyl acetate and aqueous extracts were prepared from each beer. Ale extracts were found to contain the highest level of polyphenols ( $3196 \mathrm{mg}$ gallic acid equivalents/l) and to possess the highest antioxidant activity ( $3525 \mu \mathrm{M}$ Trolox equivalent). To better characterise the polyphenol content of ale, centrifugal partition chromatography (CPC) was used to separate ale extracts into seventeen fractions, which were further analysed by reverse-phase HPLC and liquid chromatography-(electrospray ionization)-MS-MS. Measurable polyphenol content and total phenolic content within CPC fractions was shown to be positively correlated with antioxidant activity $\left(R^{2} 0.741, P<0.05\right)$. In addition, quercetin derivatives and myricetin were identified, which correlate well with antioxidant potential.

The absorption of beer prenylated flavonoids across Caco-2 cell monolayers was investigated and pH-controlled stirred batch-culture vessels were used as an in vitro model of colonic metabolism.

The anti-proliferative effect of beer phytochemicals and beer extracts on human colon adenocarcinoma cells was also investigated. Caco- 2 cells seeded in twelve-well plates $\left(1.2 \times 10^{4}\right.$ cells $\left./ \mathrm{ml}\right)$ were grown for $4 \mathrm{~d}$ before exposure to lager, ale or stout extracts $(50 \mu \mathrm{g} / \mathrm{ml})$, flavonol solutions $(1-100 \mu \mathrm{M})$ or vehicle $(1 \%(\mathrm{v} / \mathrm{v})$ methanol or $1 \%(\mathrm{v} / \mathrm{v})$ dimethyl sulfoxide) for $24,48,72$ and $96 \mathrm{~h}$ before sulforhodamine B assays (Sigma-Aldrich, Poole, Dorset, UK) were performed to evaluate total biomass. Stout produced a moderate inhibitory effect on cancer cell proliferation, whilst myricetin exerted a strong inhibitory effect.

(A)

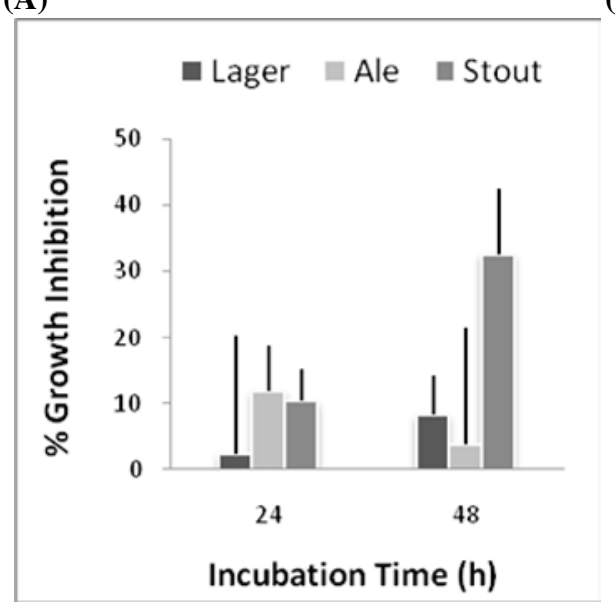

(B)

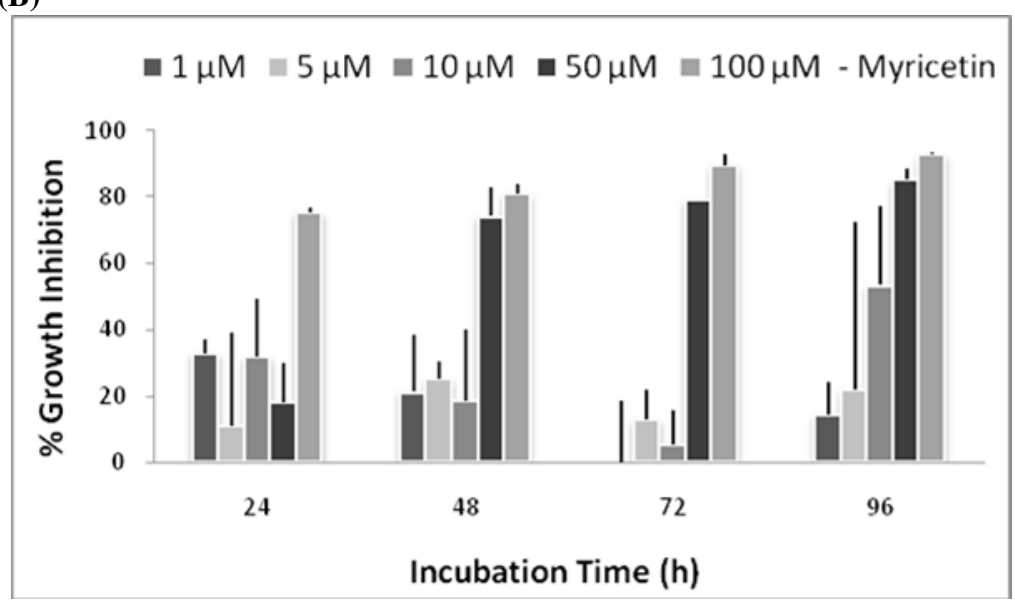

Figure. (A) Growth inhibition by beer extracts ( $n$ 9); (B) growth inhibition by myricetin ( $n$ 2). Values are means and 1 SD represented by vertical bars.

V.J.C. is in receipt of a BBSRC CASE Studentship with BRI.

1. Pascoe HM, Ames JM \& Chandra S (2003) J Am Brew Chem 61, 203-209.

2. Knekt P, Kumpulainen J, Jarvinen R et al. (2002) Am J Clin Nutr 76, 560-568.

3. Spencer JPE, Chowrimootoo G, Choudhury R et al. (1999) FEBS Lett 458, 224-230.

4. Corona G, Deiana M, Incani A et al. (2007) Biochem Biophys Res Commun 362, 606-611. 